\title{
Majorelle, un art de vivre moderne
}

Paris, Nicolas Chaudun, 2009, 208 p.

\section{Eugénie Briot}

\section{OpenEdition}

\section{Journals}

Édition électronique

URL : http://journals.openedition.org/dht/1853

DOI : $10.4000 /$ dht.1853

ISSN : 1775-4194

\section{Éditeur :}

Centre d'histoire des techniques et de l'environnement du Cnam (CDHTE-Cnam), Société des élèves du CDHTE-Cnam

\section{Édition imprimée}

Date de publication : 1 décembre 2011

Pagination : 241-242

ISBN : 978-2-9530779-7-1

ISSN : 0417-8726

\section{Référence électronique}

Eugénie Briot, "Majorelle, un art de vivre moderne », Documents pour l'histoire des techniques [En ligne], 20 | 2e semestre 2011, mis en ligne le 24 septembre 2012, consulté le 21 septembre 2020. URL : http://journals.openedition.org/dht/1853 ; DOI : https://doi.org/10.4000/dht.1853

Ce document a été généré automatiquement le 21 septembre 2020.

(c) Tous droits réservés 


\section{Majorelle, un art de vivre moderne}

Paris, Nicolas Chaudun, 2009, 208 p.

Eugénie Briot

RÉFÉRENCE

Majorelle, un art de vivre moderne, Paris, Nicolas Chaudun, 2009, 208 p 
1 Après Victor Prouvé (1858-1943), célébré en 2008, la ville de Nancy accueillait en 2009 la première grande exposition monographique rétrospective de l'œuvre de Louis Majorelle (1859-1926), à l'occasion du cent-cinquantenaire de la naissance de l'artiste. Organisée par la Ville de Nancy et le musée de l'Ecole de Nancy aux Galeries Poirel du 2 mai au 30 août 2009, sous le commissariat de Roselyne Bouvier (Professeur d'histoire de l'art à l'Ecole supérieure d'art d'Epinal) et de Valérie Thomas (Conservateur en chef, Musée de l'Ecole de Nancy), l'exposition "Majorelle, un art de vivre moderne" rassemblait 170 pièces, des premières productions de Louis Majorelle aux

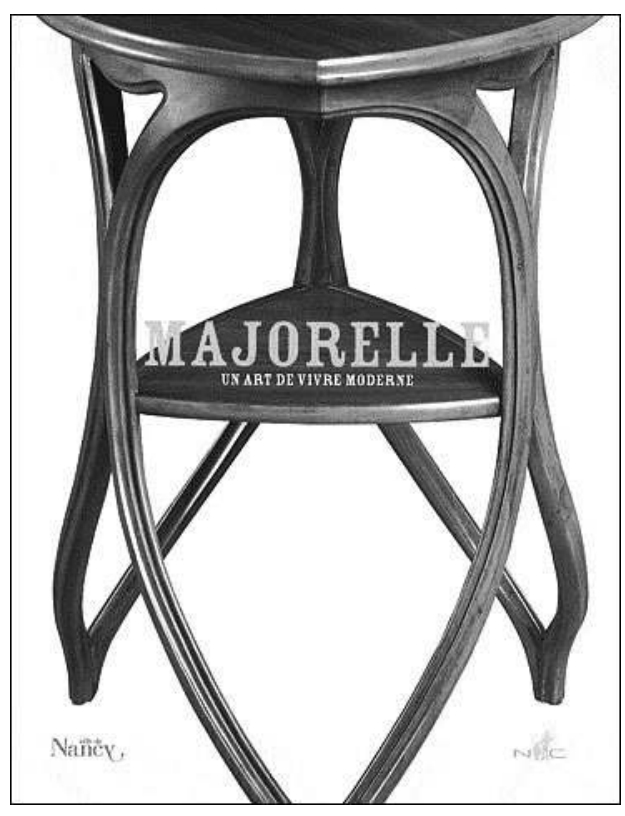
meubles et objets conçus par ses continuateurs, frères, neveux et collaborateurs, de 1926 à la fermeture des ateliers nancéiens en 1956. Le très beau catalogue de l'exposition, édité par la maison Nicolas Chaudun, offre avec beaucoup de bonheur un prolongement à la visite en invitant à découvrir plus précisément l'œuvre de l'artiste, la replaçant dans le contexte industriel, artistique et critique de son temps, et proposant un état des lieux de sa représentation dans les collections d'arts décoratifs nationales.

Né à Toul en 1859, Louis Majorelle travaille d'abord dans la lignée de son père, Auguste, spécialisé dans la décoration de mobilier dans le style japonais (meubles laqués façon vernis Martin) et la copie de style. En 1879, au décès de celui-ci, Louis prend à Nancy la direction de l'entreprise familiale, qui emploie une vingtaine d'ouvriers et bénéficie, au lendemain de l'annexion de l'Alsace et de la Moselle, de conditions économiques favorables. Influencé par les productions d'Emile Gallé, sans pour autant abandonner la production industrielle de copies de style, Louis Majorelle se tourne vers la fabrication d'un mobilier moderne, dont les lignes sont inspirées par la nature. Il devient ainsi l'un des chefs de file de l'Ecole de Nancy et de l'Art Nouveau. A partir de 1898, les activités d'ébénisterie de la maison Majorelle sont complétées par un atelier de ferronnerie, dont les pièces, plaques de propreté, serrures, ferronneries architecturales, et applications de bronze, soulignent la structure des meubles avec élégance. Le savoirfaire, le style et la renommée de Majorelle sont consacrés en 1912 par la commande de la grande rampe monumentale des Galeries Lafayette à Paris. En 1902, Majorelle entame une collaboration avec Antonin Daum pour la production de luminaires associant au verre le fer forgé. A la disparition de Louis Majorelle en 1926, Alfred Lévy, son collaborateur (1873-1955), prend la direction artistique de la maison, tandis que son frère Jules, puis son fils Jean, ont en charge la gestion financière. Pendant trente ans, d'importantes commandes d'aménagement de bureaux, de navires comme le Normandie (appartements du commandant et 48 cabines de première classe), ou de grands magasins sont honorées par les ateliers Majorelle de la rue du Vieil Aître, jusqu'à la leur fermeture en 1956. 
3 La pérennité et les succès de Majorelle, pendant près d'une centaine d'années, en font ainsi un sujet exemplaire des liens entre les arts, l'industrie, les technologies, le commerce et le management. Renonçant à une approche chronologique de la production de Majorelle, l'exposition était articulée en quatre sections : « Majorelle, un savoir-faire", "Le meuble d'art ", "Du dessin à l'image publicitaire commerciale ", «Objets d'art, objets de diffusion» et « Majorelle ensemblier ». La partie de l'ouvrage consacrée au catalogue des œuvres exposées (pp.177-207), reproduites dans leur ensemble, reprend logiquement le découpage de l'exposition, chaque thématique étant introduite par une courte présentation.

4 L'ouvrage s'ouvre auparavant sur une mise en perspective de l'œuvre de Majorelle dans l'histoire industrielle et artistique de son temps, à travers quatre contributions d'Olivier Gabet, ( $\mathrm{Du}$ faubourg Saint-Antoine à Nancy»), Jérôme Perrin («La production art nouveau de Majorelle sous la plume de la critique »), Roselyne Bouvier ("De l'Art Déco au style Moderne») et Christophe Bardin («Daum et Majorelle, une collaboration exemplaire »). Deux contributions complémentaires de Valérie Thomas ("Majorelle dans les collections du musée de l'Ecole de Nancy») et Philippe Thiébaut (" Majorelle dans les collections du musée d'Orsay »), respectivement conservateurs en chef du musée de l'Ecole de Nancy et du musée d'Orsay apportent enfin un éclairage sur la place des productions de Majorelle dans deux collections nationales majeures d'Art Nouveau. Une chronologie détaillée et abondamment illustrée, ainsi qu'une riche bibliographie complètent utilement l'ensemble.

5 La qualité des illustrations, enfin, mises en valeur par l'originalité d'une mise en page claire, gaie et aérée, font de la lecture de ce catalogue d'exposition un moment aussi agréable qu'enrichissant.

\section{AUTEUR}

\section{EUGÉNIE BRIOT}

IRG, Université Paris-Est-Marne-la-Vallée 